\title{
O livro Programa de saúde: um caso de censura durante a ditadura militar brasileira
}

\author{
Programa de saúde: a case of book censorship \\ during the Brazilian military dictatorship
}

\section{Sandra Reimão}

Professora da Escola de Artes, Ciências e Humanidades e do Programa de Pós-graduação em Comunicação da Escola de Comunicações e Artes/ Universidade de São Paulo. Rua Arlindo Béttio, 1000 03828-000 - São Paulo - SP - Brasil sandra.reimao@gmail.com
REIMÃO, Sandra. O livro Programa de saúde: um caso de censura durante a ditadura militar brasileira. História, Ciências, Saúde - Manguinhos, Rio de Janeiro, v.20, supl., nov. 2013, p.1393-1401.

Resumo

Estão liberados para consulta alguns documentos produzidos por órgãos do governo durante a ditadura militar brasileira, entre eles, pareceres de censura sobre televisão, rádio, teatro, filmes, músicas, publicidades e impressos. Entre os cerca de quinhentos pareceres relativos a livros está o indicativo de veto a Programa de saúde: projetos e temas de higiene e saúde, obra didática que propunha ações para que os alunos buscassem conhecer suas realidades sanitárias e pudessem adquirir conhecimentos e comportamentos saudáveis nessa área. $\mathrm{O}$ argumento para o veto alegava que a informação poderia cair em mãos de professores mal preparados que a deturpariam, e isso poderia causar sérios problemas à juventude brasileira. Nesse parecer vemos, por parte do Departamento de Censura e Diversões Públicas, uma postura obscurantista e elitista que procurava evitar a circulação da informação e cercear o debate.

Palavras-chave: saúde pública; saneamento; higiene; ditadura militar; Brasil.

\section{Abstract}

Some documents produced by the government during the Brazilian military dictatorship have been made available for reference, including censors' reports on television and radio programs, plays, films, songs, advertisements and printed matter. Of the 500 or so reports on books, there is one that vetoes Programa de saúde: projetos e temas de higiene e saúde, an educational work that proposed actions to help students understand their sanitary conditions and acquire knowledge about health and health-promoting habits in this area. The argument for vetoing it was that the information could fall into the hands of poorly trained teachers, who could distort its content, causing serious damage to Brazilian youth. In this report we see evidence of the obscurantist, elitist posture adopted by the Department of Censorship of Public Entertainment, which aimed to restrict the circulation of information and curb debate.

Keywords: public health; sanitation; hygiene; military dictatorship; Brazil. 
A ditadura militar brasileira (1964-1985) apresenta algumas especificidades em relação a várias outras ditaduras latino-americanas de épocas próximas; destacadamente note-se que, no Brasil, os ditadores tentaram, com maior ou menor empenho, construir um aparato de simulação de legalidade.

Os líderes militares brasileiros queriam evitar comparações com as ditaduras em outros países latino-americanos - conhecidos como banana republics. Nesse sentido, Inimá Simões (1998, p.87), referindo-se especificamente ao governo Castello Branco (1964-1967), destaca, no entanto, que: "Todo o esforço que o grupo moderado de Castello Branco fazia para apresentar ao mundo um regime militar diferenciado das Banana Republics, respeitoso portanto em relação às instituições, sumia a cada intervenção desastrada desses militares, chamados 'gorilas' pela esquerda" (destaque no original).

O presidente Castello Branco chegou a enviar um bilhete a seu chefe do gabinete militar manifestando-se contra a apreensão de livros e a prisão do editor e proprietário da Editora Civilização Brasileira, Ênio Silveira, filiado ao Partido Comunista Brasileiro. Elio Gaspari (2002, p.91, 231) descreve assim esse episódio ocorrido em maio de 1965: "Castello ... mandou ao general Ernesto Geisel quatro folhas de bloco manuscritas tratando do assunto ... Dizia o presidente ao seu chefe de gabinete militar: 'Por que a prisão do Ênio? Só para depor? A repercussão é contrária a nós ... Apreensão de livros. Nunca se fez isso no Brasil. Só de alguns (alguns!) livros imorais. Os resultados são os piores possíveis contra nós. É mesmo um terror cultural."

A censura a livros no Brasil pode, grosso modo, ser dividida em duas fases muito distintas. Na primeira, entre o golpe militar de 1964 e a decretação do ato institucional n.5 em 1968, a censura a livros foi "marcada por uma atuação confusa e multifacetada, pela ausência de critérios mesclando batidas policiais, apreensões, confisco e coerção física" (Reimão, 2011, p.20). Na fase posterior, especialmente depois de 1970, aconteceram esforços para formalizar e organizar as atividades censórias: a censura prévia para livros foi regulamentada (pelo decreto-lei n.1.077/70) e houve a concentração das atividades no Departamento de Censura e Diversões Públicas (DCDP), em Brasília (Stephanou, 2001, p.269).

O DCDP integrava esses esforços de formalização e de aparente legalidade do regime ditatorial. Nos documentos do DCDP preservados no Arquivo Nacional em Brasília há cerca de quinhentos pareceres sobre livros, um deles sobre o Programa de saúde: projetos e temas de higiene e saúde (Reimão, 2011, p.137-139).

\section{O livro}

De autoria de Lídia Rosenberg Aratangy, Silvio de Almeida Toledo Filho e Oswaldo FrotaPessoa, o livro Programa de saúde: projetos e temas de higiene e saúde, publicado pela Companhia Editora Nacional, de São Paulo, em 1975, é uma obra didática voltada para o então ensino de segundo grau, equivalente ao atual ensino médio. Como registrado nas primeiras páginas, sua finalidade era fazer os alunos "mergulharem na realidade sanitária de suas comunidades, orientados por seus professores" (Aratangy, Toledo Filho, Frota-Pessoa, p.1), acreditando que essa informação e essa percepção poderiam lhes dar "vivência necessária para a aquisição de conhecimentos genuínos e a adoção de comportamentos desejáveis nessa área" (s.p.). 
O livro se divide em duas partes: Projetos e Temas. Na primeira, são propostas cinco questões para cujas soluções os alunos devem buscar as informações necessárias. Esse método visa propiciar que o aluno se envolva de modo ativo e criador. Na segunda parte, são propostas discussões a partir de textos sobre temas. As questões de Projetos são todas relacionadas à realidade de vida dos alunos: Qual a situação sanitária de seu município?, Qual a qualidade da água com que seu município é abastecido?, Como está sendo combatida a endemia mais importante de seu município?, Como estão sendo usadas as vacinas para prevenção de doenças em seu município e Influem as verminoses no aproveitamento escolar? Os temas propostos para discussão são cinco: raiva, tétano, tuberculose, cárie dentária, drogas e comportamento.

Programa de saúde: projetos e temas de higiene e saúde, como outros livros da época, alguns escritos pelos mesmos autores, vinculava-se tanto à lei n.5.692, de 11 de agosto de 1971, que estabeleceu o ensino de saúde pública para os primeiro e segundo graus (Arelaro, 2007, p.907-908), quanto às diretrizes educacionais vigentes, que preconizavam que os docentes deviam "ensinar 'com' os alunos, isto é, mediante as atividades dos próprios estudantes" (Aratangy, Toledo Filho, Frota-Pessoa, 1975; destaque no original), como enfatizado na contracapa do livro.

\section{O parecer $n .270 / 78$}

Em 19 de outubro de 1978, duas técnicas do DCDP assinaram um parecer de duas páginas e meia indicando o veto do livro Programa de saúde: projetos e temas de higiene e saúde. Vejamos os argumentos:

O parecer reconhece que a obra didática está "exatamente" de acordo com os métodos de ensino propostos pelo Conselho Federal de Educação (CFE), reconhece também que o tema drogas "faz parte do currículo da disciplina Programa de Saúde" e que a exposição sobre o tema das drogas contida no livro é "clara, precisa e contida" (Brasil, 19 out. 1978, s.p.).

Por outro lado, o parecer salienta que o Ministério da Educação e Cultura (MEC) indica que "somente poderão ministrar cursos antitóxicos, pessoas qualificadas pelo MEC e com cartas de credenciamento fornecidas pelo referido Ministério" (Brasil, 19 out. 1978, s.p.).

Por fim, o parecer assume a posição do MEC em detrimento da do CFE para vetar o livro Programa de saúde: projetos e temas de higiene e saúde, argumentando que pode haver, por parte dos professores sem treinamento específico, má utilização das informações e isso poderia "causar sérios problemas no espírito da juventude brasileira" (Brasil, 19 out. 1978, s.p.).

\section{Considerações finais}

Conceber jovens que, supervisionados e orientados por seus professores, saiam dos muros da escola e busquem, a partir das questões propostas pelo livro didático, conhecer, entender e analisar os mecanismos políticos e de gestão de seus municípios é conceber jovens que adquiririam consciência política a partir de uma vivência concreta. Lembremos que a palavra política origina-se no adjetivo relacionado ao termo grego pólis e significa tudo que se refere "à cidade e, consequentemente, o que é urbano, civil, público e até mesmo sociável ou social" (Bobbio, Matteucci, Pasquino, 1993, p.954). 
Lembremos ainda que em 1974 a ditadura tentou impedir, e por um bom tempo conseguiu, que fossem veiculadas notícias sobre uma epidemia de meningite meningocócica de âmbito nacional, para não ter que assumir o fato de que o "país estava despreparado para enfrentar o crescente número de casos" e também não tinha capacidade "de importar, em curto prazo, a quantidade de doses de vacinas necessárias" (CCMS, s.d.).

Propiciar conhecimento e estimular os jovens a atuar em seus municípios é possibilitar uma dimensão cidadã e participativa que o sistema ditatorial vigente no país queria, firmemente, evitar.

Na tentativa de ocultar questões políticas maiores, o parecer arranja um artifício: concentrase no tema das drogas e tenta sustentar-se em um detalhe técnico menor, as indicações do MEC.

$\mathrm{O}$ argumento censório de que uma informação pode ser mal gerida é anti-iluminista e revela uma atitude tutelar do DCDP em relação a estudantes, professores e ao próprio CFE.

É importante situarmos que nas décadas de 1960 e 1970 houve um aumento mundial significativo do consumo da maconha, que desde os anos 1930 é considerada um 'problema social' (Ribeiro, 2005). É fundamental também frisarmos que o consumo excessivo de drogas é, comprovadamente, prejudicial ao indivíduo e a seu grupo social, sobretudo a sua família.

Visto o grande número de usuários no país e a gravidade dos malefícios do consumo de drogas (Noto, Galduróz, 1999), em vez de uma política de silêncio e de restrição do debate, uma postura de difusão de informações e de esclarecimentos poderia ser uma estratégia eficaz de combate ao vício.

Reforçando nosso argumento, destacamos, dentre extensa bibliografia no mesmo sentido, o artigo "Enfoque contextual das drogas: aspectos biológicos, culturais e educacionais", de Álvaro Lorencini Júnior (1998), em que ações de divulgação e discussão de informações sobre drogas no ambiente escolar são enfatizadas como possibilidades concretas de prevenção e controle do consumo de drogas:

Em termos de ações concretas, o enfoque de diminuição de riscos viabiliza-se, na prática escolar, por cinco modelos básicos: 'conhecimento científico', educação afetiva, oferecimento de alternativas, educação para a saúde e modificação das condições de ensino ...

'O modelo do conhecimento científico. Propõe o fornecimento de informações sobre drogas de modo imparcial e científico. A partir dessas informações os jovens poderiam tomar decisões racionais e bem fundamentadas sobre as drogas.' (Lorencini Júnior, 1998, p.27, destaques nossos)

O livro Programa de saúde: projetos e temas de higiene e saúde acredita na participação ativa e criativa do aluno para buscar, gerir e avaliar conhecimentos, até sobre drogas. O parecer, ao contrário, quer restringir o debate, argumentando que a informação pode ser mal gerida e tornar-se prejudicial. Atitudes que bloqueiam a circulação de informação e a geração de conhecimento, mesmo que o façam em nome de conhecimento técnico mais preciso, são obscurantistas e foram numerosas nas ditaduras da segunda metade do século XX nas banana republics latino-americanas. 


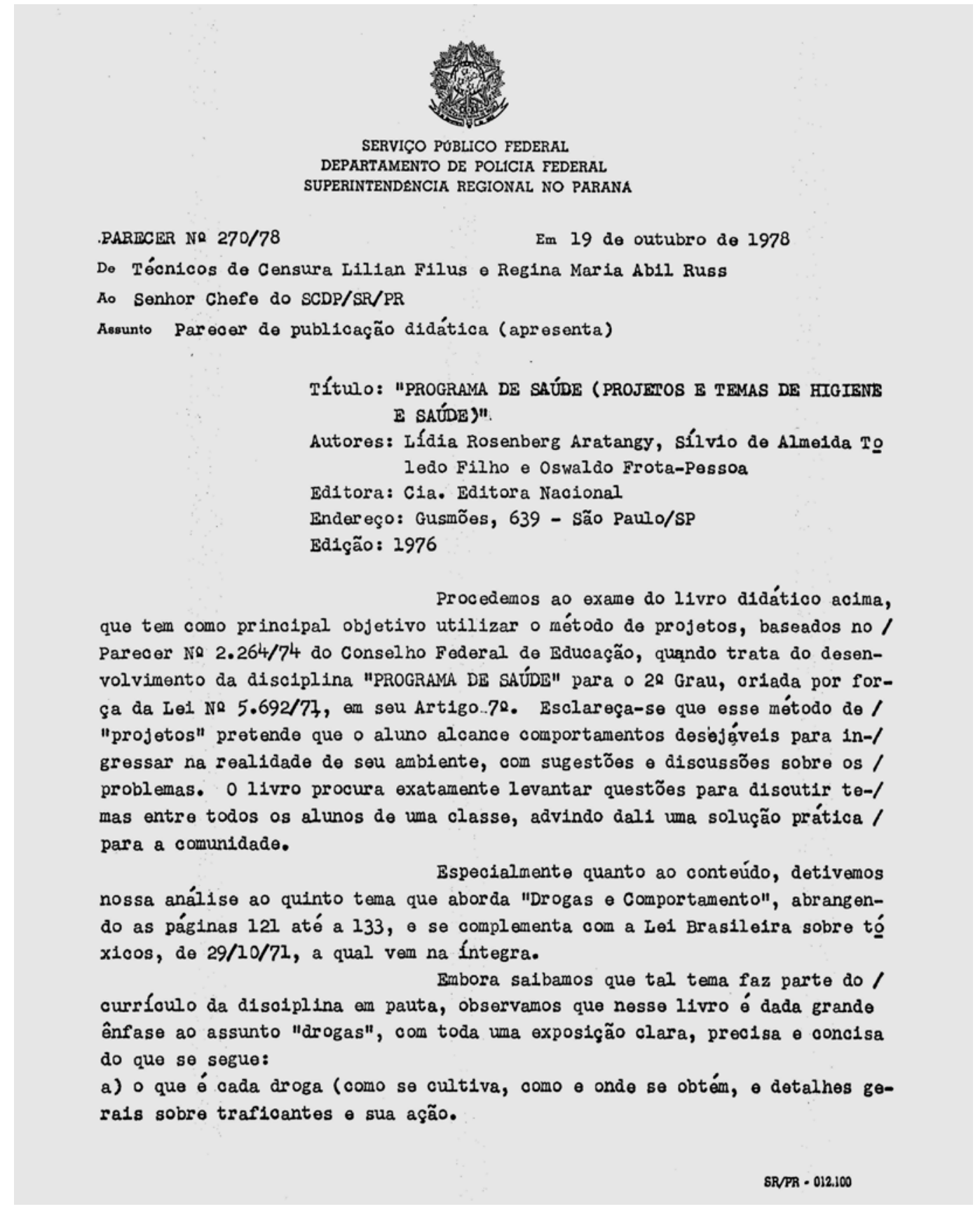

Figura 1: Página 1 do parecer sobre o livro Programa de saúde 
SERVIÇO POBLICO FEDERAL.

b) as sensações que as drogas produzem, durante o efeito.

c) a dependênola espeoífica que cada droga causa.

d) explicação dos nomes das drogas.

e) as razões que levam uma pessoa a procurar o uso de drogas.

f) as consequêneias do uso de entorpecentes - física, mental, psíquica.

g) ○ problema sob o aspecto policial e médico: é oriminoso ou doente?

\section{COLOCACÃO LEGAL:}

O Decreto Ne 69.845 de $27 / 12 / 71$ que regulamen ta a Lei No 5.726 de 29/10/71, diz em seusArtigos 12 e 13 que o Minlstério da Eđucação e Cultura - M.E.C. - coordenará e executará programas de esclareo1-/ mento popular através do Conselho de Prevenção Antitóxico. Im seu Art1go 16 - seus parágrafos dispõe sobre o pessoal que estará habilitado a ministrar / oursos spbre tóxicos, isto é, educadores espeoificos para orientar pais, médi. cos e alunos no âmbito escolar. Para efeito deste Artigo acima, somente poderão ministrar cursos ant1tóxicos, pessoas devidamente qualificadas pelo MEC $\theta$ com cartas de credenoiamento fornecidas pelo referido Ministério.

No Artigo 18 o MEC determina que se inoluirá na Disoiplina "Educação Moral e Cívica" a realização de palestras visando ०/ esclarecimento quanto ao uso nocivo de substânolas entorpecentes.

\section{PARECER FINAL.}

1) Após consultas a órgãos competentes, obt1vemos confirmação de que os livros didáticos são lançados no mercado para uso de professores e alunos em colégios, sem prévía análise ou aprovação do MEC,/ podendo qualquer professor utilizar em sua classe o livro que lhe aprouver.

2) Normalmente, cada professor aconselha aos alunos a publicação que julgar conveniente para o melhor aproveltamento na dis oiplina que leciona.

3) Os autores do livro analisado são doutores em Biologia e podem estar credenolados pelo MEC a lecionar sobre tóxioos, porém são imprevisf́veis os enfoques que cada professor de "programa de Saúde" / que venha a utilizar tal publicação, dê ao problema, enfatizando que a ma1oria não possui este credenciamento acima c1tado.

4) Como a abordagem do tema "Drogas" é regida por le1 específica, observadas todas as precauções quanto ao tipo de platéla - 1dade, meio social, meio psicológico -, julgamos perigoso o uso generalizadc do texto deste livro em escolas, já que se destina a adolescentes de 15 a 18 anos, no caso, os mais suscetíveis de querer experimentar o proib1do, po1s é a Idade da busca de liberdade, $\theta$ todas as gamas de sensação, de perigo $\theta$ de aventura estão presentes.

5) No limitado oampo de professores que oonhecemos, o onde basermos nosso pareoer por amostragem, espeoifloamento da regi- 
SERVIÇO POBLICO FEDERAL.

ão de Curitiba, estimamos que não há grande húmero de credenolados a manejar esse texto do livro, conforme a exigência do MEC, sendo a ma1oria dos que m1nistram aulas de "Programas de Saúde", lioenciados por faculdade na área de / Ciências Biológicas.

6) O temor de que a má ut1lização, por pessoas não qualifioadas para palestrar sobre "Drogas", usando a abordagem tão ampla que a publicação apresenta, possa causar sérios problemas no espírito da juventude brasileira, é que nos manifestemos contrários à sua venda e uso indisoriminados.

É nosso Parocor.
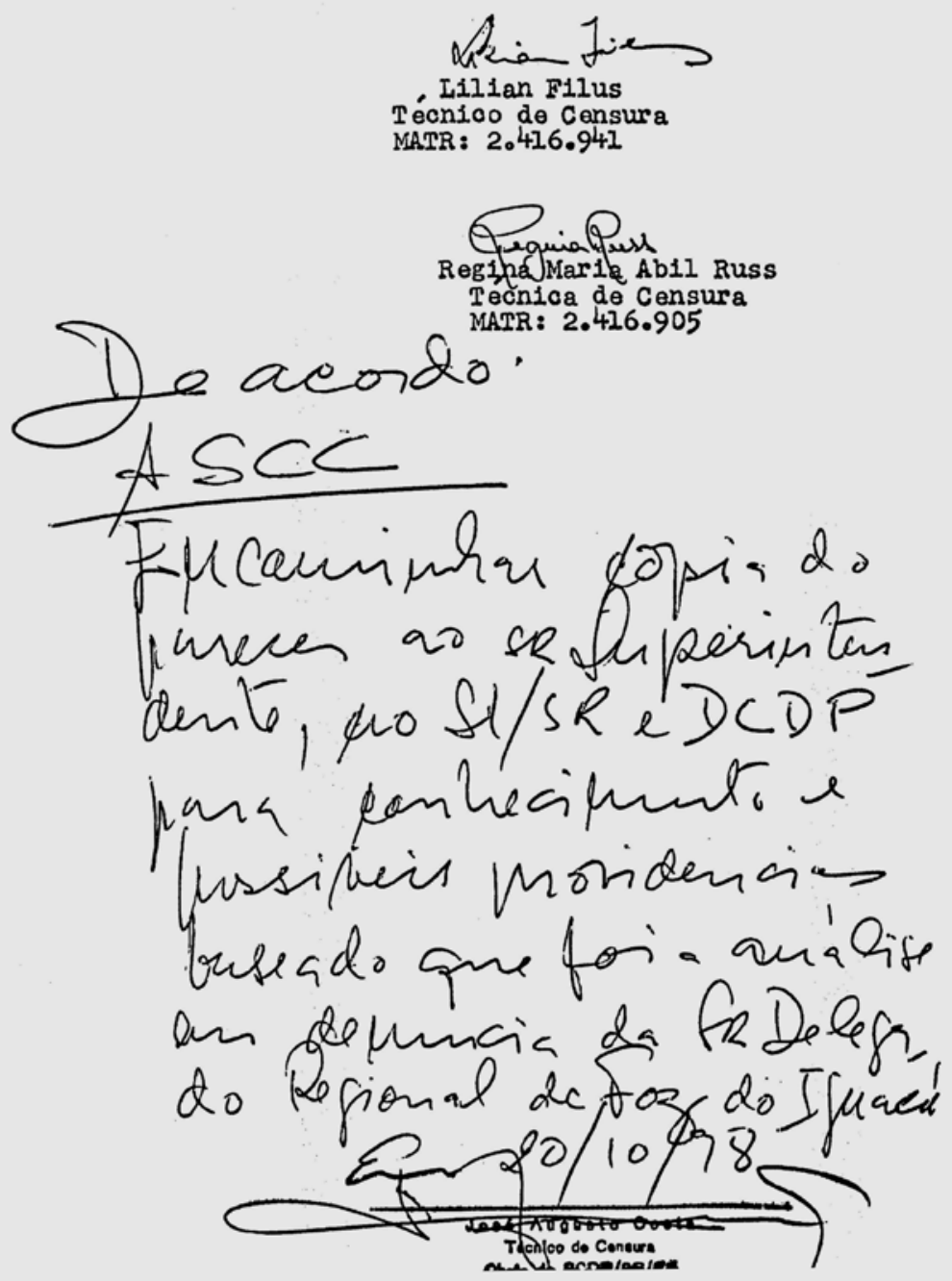

Figura 3: Página 3 do parecer sobre o livro Programa de saúde 


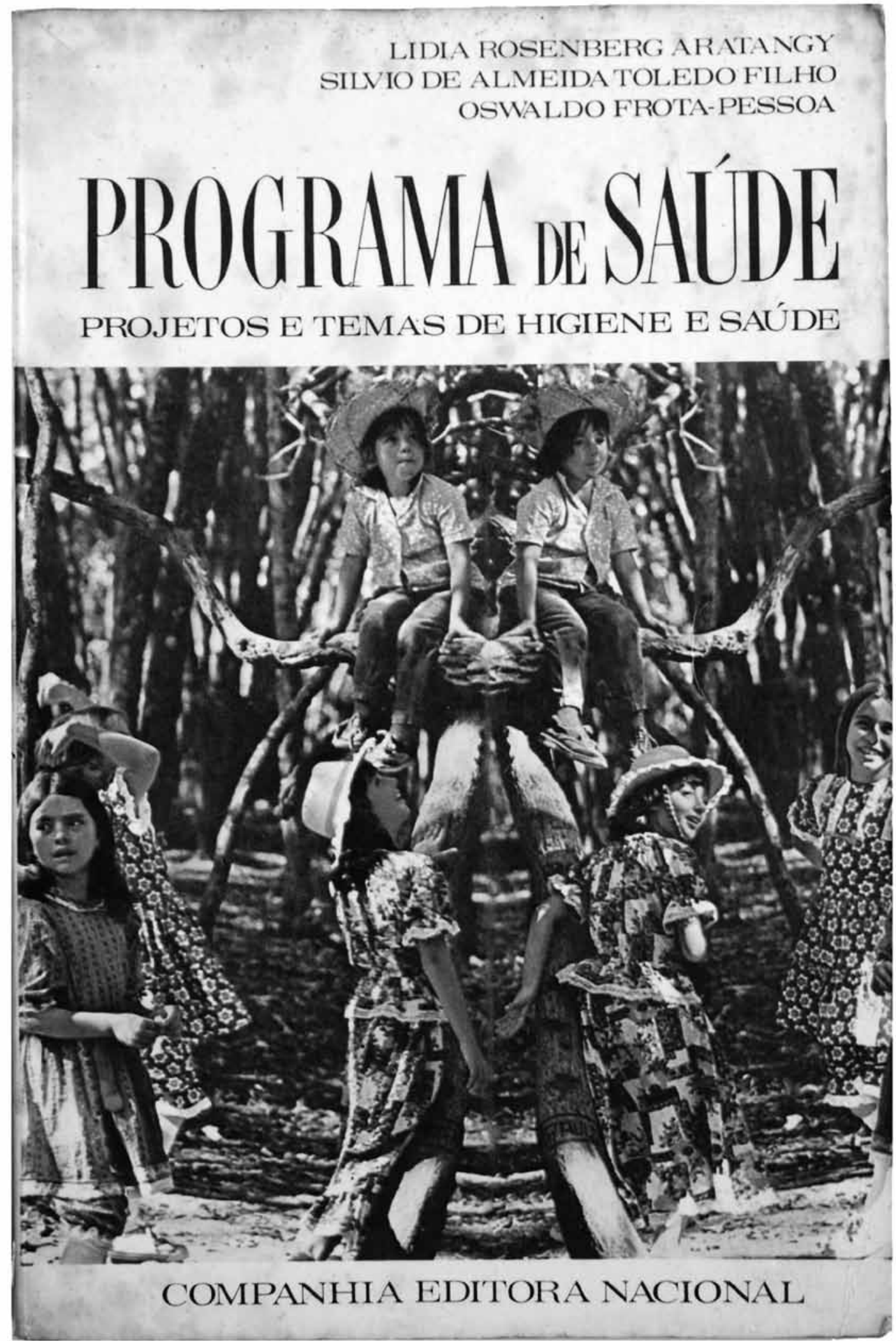

Figura 4: Capa do livro Programa de saúde 


\section{REFERÊNCIAS}

ARATANGY, Lídia R.; TOLEDO FILHO, Silvio de A.; FROTA-PESSOA, Oswaldo.

Programa de saúde: projetos e temas de higiene e saúde. São Paulo: Companhia Editora Nacional. 1975.

ARELARO, Lisete R.G.

Formulação e implementação das políticas públicas em educação e as parcerias públicoprivadas: impasse democrático ou mistificação política. Educação e Sociedade, Campinas, v.28, n.100 especial, p.899-919. Disponível em: http://www.cedes.unicamp.br. Acesso em: 19 out. 2012. 2007.

BOBBIO, Norberto; MATTEUCCI, Nicola; PASQUINO, Gianfranco.

Dicionário de política. Brasília: Editora UnB. 1993.

BRASIL.

Departamento de Polícia Federal.

Superintendência Regional no Paraná. Parecer n.270/78, de 19 de outubro de 1978. Divisão de Censura de Diversões Públicas; Censura Prévia; Publicações. (Arquivo Nacional de Brasília). 19 out. 1978.

CCMS.

Centro Cultural do Ministério da Saúde. [Folheto de apresentação da produção de Manguinhos].

Disponível: http://www.ccms.saude.gov.br/ revolta/pdf/M9.pdf. Acesso em: 20 fev. 2012. s.d.

GASPARI, Elio.

A ditadura envergonhada. São Paulo: Companhia das Letras. 2002.
LORENCINI JÚNIOR, Álvaro.

Enfoque contextual das drogas: aspectos biológicos, culturais e educacionais. In: Aquino, Julio Groppa. Drogas na escola: alternativas teóricas e práticas. São Paulo: Summus. 1998.

NOTO, Ana Regina; GALDURÓZ, José Carlos. O uso de drogas psicotrópicas e a prevenção no Brasil. Ciência e Saúde Coletiva, São Paulo, v.4, n.1, p.145-151. 1999.

REIMÃO, Sandra.

Repressão e resistência: censura a livros na ditadura militar. São Paulo: Edusp; Fapesp. 2011.

RIBEIRO, Marcelo et al.

Abuso e dependência da maconha. Revista da Associação Médica Brasileira, São Paulo, v.51, n.5. Disponível em: http://www.scielo. br/scielo.php?script=sci_arttext\&pid=S010442302005000500008\&lng=en\&nrm=iso. Acesso em: 8 fev. 2013. 2005.

SIMÕES, Inimá.

Roteiro da intolerância. São Paulo: Senac; Terceiro Nome. 1998.

STEPHANOU, Alexandre Ayub.

Censura no regime militar e militarização das artes. Porto Alegre: EdiPUCRS. 2001.

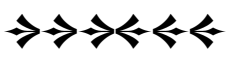




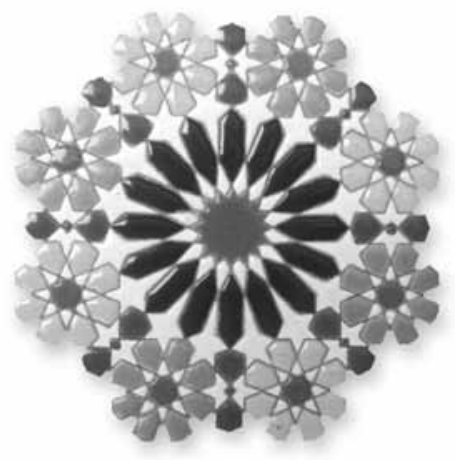

